\title{
A STUDY IN VULCANIZATION OF NEOPRENE RUBBER (WRT) BY POLYMETHYLOL RESIN (RESOL)
}

\author{
Mohammed Ali Mutar \\ Department of Chemistry, College of Education, Al-Qadisiya University, Iraq.
}

\begin{abstract}
The vulcanization of neoprene (WRT) with different loading of polymethylol resin (Resol) was investigated to understand the role of resol as curing agent. The cure rate fasted when resol was added to the rubber compound, and the change in the mechanical properties were significant. An improvement in mechanical properties were seen with $7.5 \mathrm{phr}$ loading of resol, while an adverse effect observed only with a high loading at $10 \mathrm{phr}$ and in absence of magnesia and zinc oxide from rubber compound. Rubber compounds containing different loading of resol show slight decrease in tensile strength, elongation, and tear strength values after 5 days at $80 \mathrm{C}^{\circ}$, while high increase in hardness and modulus at the same conditions.
\end{abstract}

Keywords: Neoprene, resol, vulcanization.

\section{Introduction}

The vulcanization chemistry of chloroprene rubbers is fundamentally different from that of the other diene rubbers. The carbon-carbon double bonds in the polychloroprene chain are deactivated by the presence of the electronegative chlorine atoms, and one consequence of this is that vulcanization by heating with sulfur occurs to a very limited extent only ${ }^{1}$. The reactivity of the chlorine atom varies according to its position relative to the other atoms in an organic molecule. It has been well established that reactivity increases in the following order:

\section{Tertiary allylic $>$ Allylic $>$ Tertiary $>$ Vinylic}

Highly reactive tertiary allylic chlorine is present in neoprene as a result of 1-2 polymerizations. This labile chlorine which comprises about $1.6 \%$ of the total chlorine in NEOPRENE $\mathrm{W}$ makes possible the rapid curing of neoprene with many classes of organic accelerators (e.g., diamines, dihydric phenols or derivatives, aminophenols, thioureas, thioamides $)^{2}$. Neoprene mixes, unlike mixes based on other diene rubbers, are cured not with sulfur but with metallicoxides ${ }^{3}$. Neoprene compounds which contain no zinc oxide do not vulcanize readily even though an organic accelerator is present. Additional supporting evidence for the catalytic nature of zinc chlorides is provided by the types of cure retarders which are effective in neoprene ${ }^{4}$. They may be classified into two groups: (1) those which compete with zinc oxide for hydrogen chloride, such as magnesia; and (2) those which reduce the catalytic activity of zinc chloride by coordination, such as water and aromatic secondary amines.

When no organic accelerator is present in NEOPRENE $\mathrm{W}$, only partial vulcanization occurs with metallic oxides. The nature of the crosslinks which do form, however, is not known. The following equation represents a possible reaction but there is no evidence to prove the existence of ether bridges 5 .

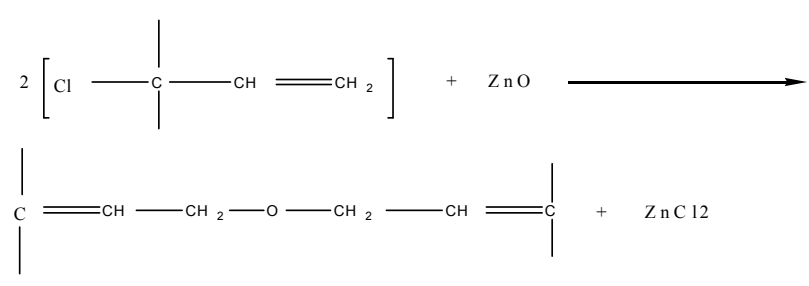

Scheme (1).

Another possible mechanism may involve the formation of $\mathrm{ZnCl}_{2}$, first by reaction of the $\mathrm{ZnO}$ with $\mathrm{HCl}$ released from the neoprene by oxidation attack, followed by a Freidel Crafts type reaction involving the $\mathrm{ZnCl}_{2}{ }^{6}$. Sulfur can be used with mercaptan-modified grades of neoprene as an additional curing agent, though this raises the degree of cure. Chloroprene rubbers can be crosslinked by using an organic accelerator in addition to the combination of zinc and magnesium oxides.

A well-known example of an organic accelerator for the vulcanization of chloroprene rubber is 2-mercaptoimidazoline, also known as ethylene thiourea. This 
accelerator can either be used alone or in conjunction with a thiazole or a thiuram disulfide accelerator ${ }^{7}$. Sulfur can also be used to assist the vulcanization of the non-sulfurmodified chloroprene rubbers. It is commonly used in conjunction with a thiazole and a thiuram disulfied; 2-mercaptoimiddzoline may also be added ${ }^{8}$. Chloroprene can also be crosslinked by heating with polyamines. The reaction probably involves the allylic chlorine atoms again. The hydrochloric acid formed in this reaction then reacts with zinc or magnesium oxides if these are present in the rubber compound 9 .

The remarkable improvement in chemical and physical properties of rubber after vulcanization with sulfur $^{10}$ was discovered jointly by Good year and Hankocok in the early 1840. Resols are usually made from formaldehyde mixture in which there is a molar excess of aldehyde. They differ from Novolaks in that they certain methylol groups. Diene rubbers can be cross-linked by compounds of general structure.

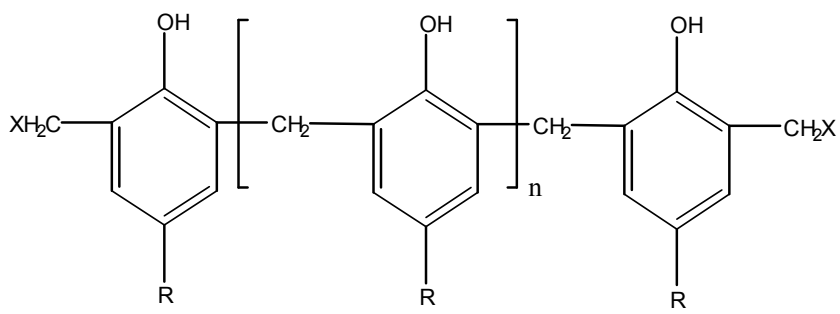

$n=0,1,2$

$X=O H$, Halogen

$\boldsymbol{R}=$ Hydrocarbon residue

\section{Scheme (2) : Polymethylol resin (Resol).}

Phenolic resins vulcanize natural and synthetic (e.g styrene-butadien rubber and nitrile rubber) without other additives ${ }^{11}$. However, at $155 \mathrm{C}^{\circ}$ the vulcanization time with 40 parts by weight of resin per 100 parts by weight was two hours. By adding magnesium oxide or carbon black it was found possible to reduce the proportion of resin to 30 parts by weight and the vulcanization time to one hour.

The vulcanizing action of numerous phenol formaldehyde condensates including the halogen methyl phenols. In his view crosslinked with phenol formaldehyde condensates if it is assumed to be a sort of continuation of the resin condensation accompanied by the splitting-off of water ${ }^{12}$. Resins cures are slower than accelerated sulfur cures and higher temperatures are required, but they can be activated by zinc oxide and halogen atoms in position $\mathrm{X}^{13}$.

In this article, the curing agent used consists of polymethylol resin (Resol). The loading amount of resol used were 3, 5, 7.5, and $10 \mathrm{phr}$. We have studied the curing of WRT rubber by resol as curing agent. The effect of Zinc oxide on curing was studied. The effect of aging on the mechanical properties also was studied.

\section{Experimental}

\section{Materials}

The grade of Chloroprene (WRT type) was used in this study, Copolymer of Chloroprene and 2, 3-dichloro-1, 3-butadiene. In this research, vulcaresin (polymethylol resin) was used as curing agent from Sartomer Company.

\section{Preparation of the Rubber Compounds}

Four rubber compounds with different loading amounts of resol were prepared. The loading amounts of resol used were 3, 5, 7.5, and $10 \mathrm{phr}$ (See Table (1)). The rubber mixes, based on different loading of resol, were prepared on a two-roll mill: rolls dimensions are: outside diameter $150 \mathrm{~mm}$, working distance $300 \mathrm{~mm}$, speed of the slow roll 24 rpm and gear ratio 1.4. Curing was carried out at a temperature of $195 \mathrm{C}^{\circ}$. The curing time was 50 minutes for rubber compounds.

Rheocurves were recorded using a Monsanto Rheometer ODR 2000 at $160 \mathrm{C}^{\circ}$ the 190 time, which denotes the time for $90 \%$ cure and the maximum torque were determined from the rheographs.

The hardness of vulcanizates was measured using a Shore A durometer according to ASTM D-2240; tensile properties were determined by a tensile tester (tensometer 10) according to ASTM D-412. The samples were thermally aged at $80 \mathrm{C}^{\circ}$ for 5 days in conventional oven. 
Table (1)

Composition of Rubber Compounds Prepared.

\begin{tabular}{|lccccc|}
\hline Ingredients & 1 & 2 & 3 & 4 & 5 \\
& $P h r$ & $P h r$ & $P h r$ & $P h r$ & $P h r$ \\
& & & & & \\
\hline WRT & $\mathbf{1 0 0}$ & $\mathbf{1 0 0}$ & $\mathbf{1 0 0}$ & $\mathbf{1 0 0}$ & $\mathbf{1 0 0}$ \\
Zinc oxide & $\mathbf{5}$ & $\mathbf{5}$ & $\mathbf{5}$ & $\mathbf{5}$ & - \\
Magnesia & $\mathbf{4}$ & $\mathbf{4}$ & $\mathbf{4}$ & $\mathbf{4}$ & - \\
6PPD & $\mathbf{1}$ & $\mathbf{1}$ & $\mathbf{1}$ & $\mathbf{1}$ & $\mathbf{1}$ \\
Aromatic oil & $\mathbf{1 0}$ & $\mathbf{1 0}$ & $\mathbf{1 0}$ & $\mathbf{1 0}$ & $\mathbf{1 0}$ \\
HAFN326 & 50 & 50 & 50 & 50 & 50 \\
Resol & $\mathbf{3}$ & $\mathbf{5}$ & $\mathbf{7 . 5}$ & $\mathbf{1 0}$ & $\mathbf{7 . 5}$ \\
\hline
\end{tabular}

\section{Results and Discussion}

\section{Cure Properties of Resol-Containing Rubber Compound}

The cure rates of the rubber compounds varied with the loading amount of resol as listed in Table (2). The t90 time increased with an increase in the loading amount of resol, while the increase in tS2 time was relatively small.

The maximum torque increased highly with an increase in resol loading up to $10 \mathrm{phr}$. The viscosity of the rubber compound also varied with the resol loading. Good scorch safety and no reversion are obtained in the presence of resol. Inspection of the data in the absence of zinc oxide and magnesia at $7.5 \mathrm{phr}$ load of resol show that there are high variations in these cure properties. Maximum torque, t90, and $\mathrm{tS} 2$ values are the highest (see Table (3)). This may be due to the two moles of hydrogen chloride formed as a result of bisalkylation without neutralization by the magnesia and zinc chloride. The use of four parts of magnesia and five parts of zinc oxide produces a good balance between processing safety and cure rate.

Table (2)

Cure Properties of the Rubber Compounds with Different Loadings of Resol from their Rheocurves Using an Oscillating Disc-Type Rheometer at $160 \mathrm{C}^{\circ}$.

\begin{tabular}{|c|c|c|c|c|c|}
\hline $\begin{array}{l}\text { Loading amount of } \\
\text { Resol (phr) }\end{array}$ & & $\frac{\text { Time }(\min )}{\mathrm{S}^{\mathrm{a}^{\mathrm{a}}}-\mathrm{T}^{\mathrm{b}} \mathrm{b}^{\mathrm{b}}}$ & & $\frac{\text { Torque }(\mathrm{J})}{\text { Min Max }}$ & $\frac{\text { Viscosity }}{\text { moony }}$ \\
\hline 3 & 0.62 & 10.83 & 3.69 & 46.43 & 9.558 \\
\hline 5 & 0.63 & 15.29 & 4.02 & 48.13 & 10.692 \\
\hline 7.5 & 0.65 & 18.19 & 4.35 & 52.14 & 10.692 \\
\hline 10 & 0.66 & 20.00 & 4.87 & 53.00 & 10.800 \\
\hline
\end{tabular}

a Time required for $2 \%$ cure.

$b$ Time required for $90 \%$ cure.
Table (3)

Eefect of Omitting of Zinc Oxide and

Magnesia on Cure Properties of Rubber Conpounds.

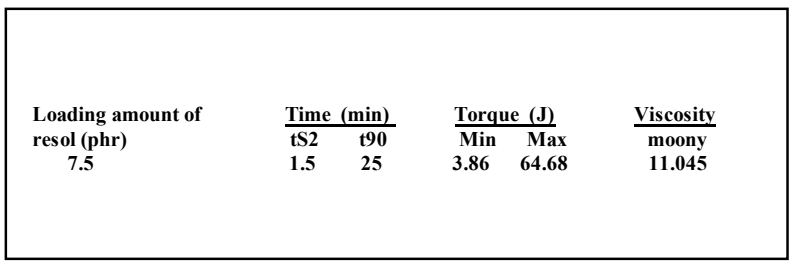

Effect of Resol Loading on the Mechanical Properties of Rubber Compounds

The change in the mechanical properties of vulcanizates with resol loading are considerable (Table (4)). Inspection of the data shows large variations in many of the properties. In particular, tensile strength (17.663-19.245 Mpa), Hardness (75-78 Shore A) and tear strength (5.510-6.133 Mpa) values vary widely. Tensile strength, hardness and tear strength values are highest for those compounds having high resol content see compounds 1, 2, and 3. This may be related to the temperature, resin acidity, structure, free phenol, formaldehyde contents, and the resin moisture content. Heating causes the reactive molecules to condense, through the reaction of methylol groups, to stable methylene links leads to the formation of three-dimensional network of resin, which interacts with rubber network. Elongation at break decreased highly with an increase in the resol loading. Optimum values of mechanical properties are obtained in the presence of $7.5 \mathrm{phr}$ of resol. An increase in resol loading above $7.5 \mathrm{phr}$ reduces the mechanical properties of WRT compounds. This may be related to the losing of the resol in main-chain modification.

Table (4)

Mechanical Properties of the Rubber Compounds with Different Loadings of Resol.

\begin{tabular}{|llclc|}
\hline & \multicolumn{3}{l|}{} \\
Compounds & 1 & 2 & 3 & 4 \\
Hardness, shore A & 75 & 76 & 78 & 77 \\
Elongation, \% & 264 & 232 & 221 & 208 \\
Tensile strength, Mpa & 17.295 & 17.663 & 19.013 & 18.142 \\
100\% modulus, Mpa & 4.344 & 4.794 & 5.529 & 6.025 \\
200\% modulus, Mpa & 11.538 & 13.120 & 15.311 & 16.623 \\
Tear strength, Mpa & 5.510 & 5.627 & 6.133 & 5.778 \\
& & & & \\
\hline
\end{tabular}


Effect of Removing of Magnesia and Zinic Oxide on the Mechanical Properties of Rubber Compounds

Inspection of the data in the absence of zinc oxide and magnesia at $7.5 \mathrm{phr}$ load of resol show that there are high variations in these mechanical properties (see Table (5)). Tensile strength, elongation at break, and tear strength are reduced, while modulus and hardness are increased in the absence of magnesia and zinc oxide. However, this may be due to the decreasing the rate of vulcanization in the absence of magnesia and zinc oxide. Zinc oxide and magnesia are used as activators in increasing the rate of vulcanization. According to this view, zinc chloride is not formed by neutralization with hydrogen chloride to catalyze the crosslinking reaction.

Table (5)

Effect of Omitting of Magnesia and Zinic Oxide on the Mechanical Properties of Rubber Compounds.

\begin{tabular}{|lc|}
\hline Compound & 5 \\
Hardness, Shore A & 83 \\
Elongation, \% & 133 \\
Tensile strength, Mpa & 13.933 \\
$100 \%$ modulus, Mpa & 8.135 \\
$200 \%$ modulus, Mpa & 16.825 \\
Tear strength, Mpa & 4.437 \\
& \\
\hline
\end{tabular}

Effect of Aging on the Mechanical Properties of Rubber Compounds

The effect of aging on the mechanical properties of rubber compounds containing different loading of resol is illustrated in Table (6). It can be seen that rubber compounds containing different loading of resol show slight decrease in tensile strength, elongation, and tear strength values after 5 days at $80 \mathrm{C}^{\circ}$ see compounds $1,2,3$ and 4 . This may be due to the enhancement of resin crosslinking on aging and the activation of the already crosslinked resin. The hardness and modulus values.

Increased highly on aging see compounds $1,2,3$ and 4 . This may be explained by the cross-linked that formed after 5 days and then approximately no bond breakage took place on aging. On omitting magnesia and zinc oxide from rubber compounds at $7.5 \mathrm{phr}$ load of resol also show slight decrease in tensile strength, elongation, and tear strength values, while higher increase in hardness and modulus values on aging. This may be explained by the fact that the delayed cross-linking can take place between the polymer chains on aging.

Table (6)

Effect of Aging on the Mechanical Properties of Rubber Compounds.

\begin{tabular}{|llcccc|}
\hline & & & & & \\
Compounds & 1 & 2 & 3 & 4 & 5 \\
Hardness, Shore A & 80 & 82 & 84 & 85 & 86 \\
Elongation, \% & 249 & 225 & 215 & 196 & 125 \\
Tensile strength, Mpa & 16.886 & 17.117 & 18.682 & 17.798 & 13.342 \\
100\% modulus, Mpa & 5.656 & 6.270 & 6.587 & 7.422 & 10.307 \\
$200 \%$ modulus, Mpa & 11.538 & 13.120 & 15.311 & 16.623 & 16.825 \\
Tear strength, Mpa & 5.379 & 5.452 & 5.950 & 5.668 & 4.248 \\
& & & & & \\
\hline
\end{tabular}

\section{Role of Resol as a Curing Agent}

It has been theorized ${ }^{14}$ that bifunctional neoprene accelerators actually become crosslinks between chloroprene polymer chains as a result of being bisalkylated by the polymer chains at the active chlorine positions. With general structure of Resol, the reaction proceeds as follows:<smiles>[R]c1cc(C=O)c(O)c(C[OH+])c1</smiles><smiles>[R]c1cc(COCC=C(C)C)c(O)c(COCC=C(C)[C+](C)Cl)c1</smiles>

Scheme (3).

The two moles of hydrogen chloride formed as a result of bisalkulation are neutralized by the magnesia and zinc oxide normally present in neoprene compounds, forming the corresponding chlorides. It is believed that zinc chloride, a strong Lewis Acid, catalyzes the crosslinking reaction. 


\section{Conclusions}

The following conclusions are derived from this study:

1. The 190 time increased with an increase in the loading amount of resol, while the increase in $\mathrm{t} 52$ time was relatively small.

2. The maximum torque increased highly with an increase in resol loading up to $10 \mathrm{phr}$. The viscosity of the rubber compound also varied with the resol loading.

3. Good scorch safety and no reversion are obtained in the presence of resol.

4. Tensile strength, hardness and tear strength values are highest for those compounds having high resol content see compounds1, 2 , and 3 .

5. Elongation at break decreased highly with an increase in the resol loading. Optimum values of mechanical properties are obtained in the presence of $7.5 \mathrm{phr}$ of resol.

6. An increase in resol loading above $7.5 \mathrm{phr}$ reduces the mechanical properties of WRT compounds.

7. Tensile strength, elongation at break, and tear strength are reduced, while modulus and hardness are increased in the absence of magnesia and zinc oxide.

8. It can be seen that rubber compounds containing different loading of resol show slight decrease in tensile strength, elongation, and tear strength values after 5 days at $80 \mathrm{C}^{\circ}$ see compounds $1,2,3$ and 4 .

9. The hardness and modulus values increased highly on aging see compounds 1, 2, 3 and 4.

On omitting magnesia and zinc oxide from rubber compounds at $7.5 \mathrm{phr}$ load of resol also show slight decrease in tensile strength, elongation, and tear strength values, while higher increase in hardness and modulus values on aging.

\section{References}

[1] W. Hofmann, Rubber Technology, Oxford University Press, UK, 1990.

[2] W.H Waddell, M.B. Rodgers. Rubber Compounding. In Kirk-Othmer Encyclopedia of Chemical Technology, $5^{\text {th }}$ Edition. 2004.

[3] A.C. Coran, Vulcanization. In Science and Technology of Rubber. $2^{\text {th }}$ Edition. Ed. J.E, Mark, B. Erman, F.R. Eirich, Academic Press. 1994.
[4] W.H. Waddell, M.B. Rodgers, The Science of Rubber Compounding. In Science and Technology of Rubber, $3^{\text {th }}$ Edition. John Wiley and Son, NY. 2005.

[5] P.R., Johnson, Rubber Chem. and Tech., Vol. 49, No. 3, 1976.

[6] J.C. Scott, G.D.F. White, D.J. Thom, R.A. Whitney, W. Hopkins. J. Polym. Sci. Part A, Polymer Chemistry. Vol 41. 2003. 1915-1962.

[7] M.P. Ferrandino, J.A. Sanders, S.W. Hong, Tetrabenzylthiuram disulfide: A Secondary Accelerator for Stable Crosslink Systems in Tire Applications. Presented at a meeting of the American Society Rubber Division, Philadelphia. 1995.

[8] T. Kuhlmann, A new Thiuram acceleration without dangerous and volatile nitrosamines. Kautschuk Gummi Kunststoffe, Volume 42, 1989. P 878-9.

[9] J.A. Dean, Lange's Handbook of Chemistry. $14^{\text {th }}$ Edition . McGraw-Hill. New York. 1992.

[10] P. W. Harris and S. Nayak, 'Resins from Alkyl phenols for the Tyree Industry and Non - Tyre Rubber Industry', Success through Technology, Indian Rubber Institute, Kerala Branch, Allied Publishers, Ltd., New Delhi, (1994).

[11] R. A. Follansbee, J. A. Koutsky, A. W. Christiansen, G. E. Myers, and R. L. Geimer, "Development of Dynamic Mechanical Methods to Characterize the Cure State of Phenolic Resol Resins". J. Appl. Polym. Sci. 47, 1993, 1481 - 1496.

[12] B. Struk, Tackifying, Curing, and Reinforcing Resins. In Rubber Technology Compounding and Testing for Performance. Edited by J.S. Hanser, Cincinnati 2001.

[13] M.G. Kim, W.L.S. Nieh, R.M. Meacham, Study on the curing of phenolformaldehyde resol resins by dynamic mechanical analysis. Ind. Eng. Chem. Res. 30, 1991, 798-803.

[14] M. Mori, J.L. Koenig, A Review of HighResolution NMR Studies of Vulcanized Elastomers in Annual reports on NMR Spectroscopy, Academic Press, New York, 1997. 
الخلاصة

تمت دراسة فلكنة النيوبرين WRT بو اسطة اسـتخدام

كميات مختلفـة هـن الريـزول (Polymethylol resin)

وذلك بهف اكتثاف دور الريزول كمادة مفلكنة. وورجد إن لن

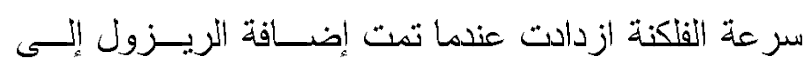

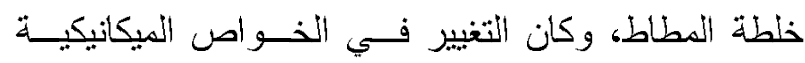
ملحوظا". ولوحظ حصول تحسن في الخواص الميكانيكيـة

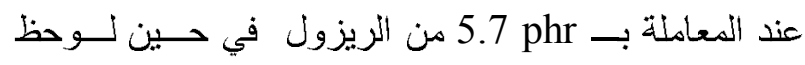

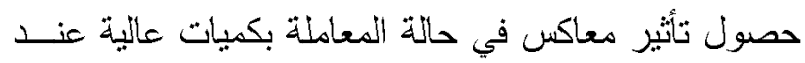
10 phr المطاط. ووجد إن خلطة المطاط التي تحتوي كميات مختلفة

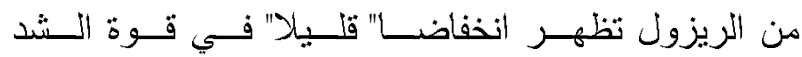
و الاسنطالة وقوة التمزق بعد 5 أيام عند 80 مثه في حـين

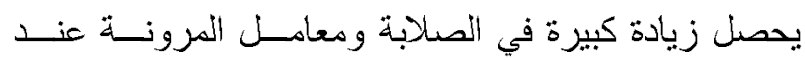
الظروف نفسها. 